\title{
Simulation of the natural draft for test bench measurements
}

\author{
Dennis Krüger ${ }^{1}$ (D) $\cdot$ Volker Lenz $^{1} \cdot$ Tobias Ulbricht $^{1}$
}

Received: 12 December 2018 / Revised: 7 October 2019 / Accepted: 10 October 2019 /Published online: 15 November 2019

(C) The Author(s) 2019

\begin{abstract}
Single room heaters are usually type tested with constant draft and are allowed under these conditions. However, the mode of operation of the user's firing usually deviates significantly from these conditions of approval, since these are operated in most cases by natural draft and not by constant draft. Since the repeatability of natural draft is hardly given due to the changing environmental conditions, a simulation has been developed, which can simulate the natural draft with high accuracy. Thus, it is basically possible to replicate the natural draft with constant environmental conditions and to use it for test bench measurements. It is a purely physical simulation that does not require any calibration parameters. Chimney geometry and environmental boundary conditions, such as the outside temperature, can be chosen freely. In addition, the cost of the necessary hardware is very low, since the system only needs cheap thermocouples, pressure sensors, and a small USB module for data acquisition.
\end{abstract}

Keywords Natural draft $\cdot$ Simulation $\cdot$ Test bench $\cdot$ Emission $\cdot$ Wood $\cdot$ Biomass

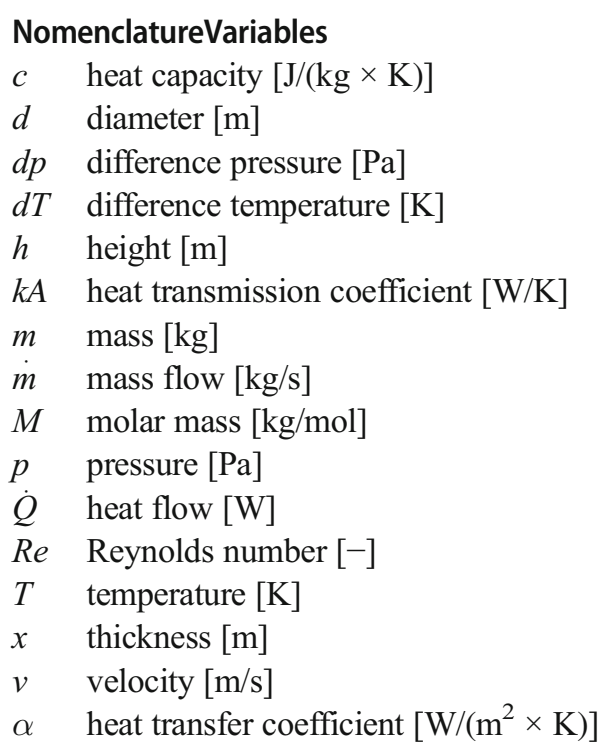

Electronic supplementary material The online version of this article (https://doi.org/10.1007/s13399-019-00531-0) contains supplementary material, which is available to authorized users.

Dennis Krüger

dennis.krueger@dbfz.de

1 Deutsches Biomasseforschungszentrum gemeinnützige $\mathrm{GmbH}$, Torgauer Straße 116, 04347 Leipzig, Germany

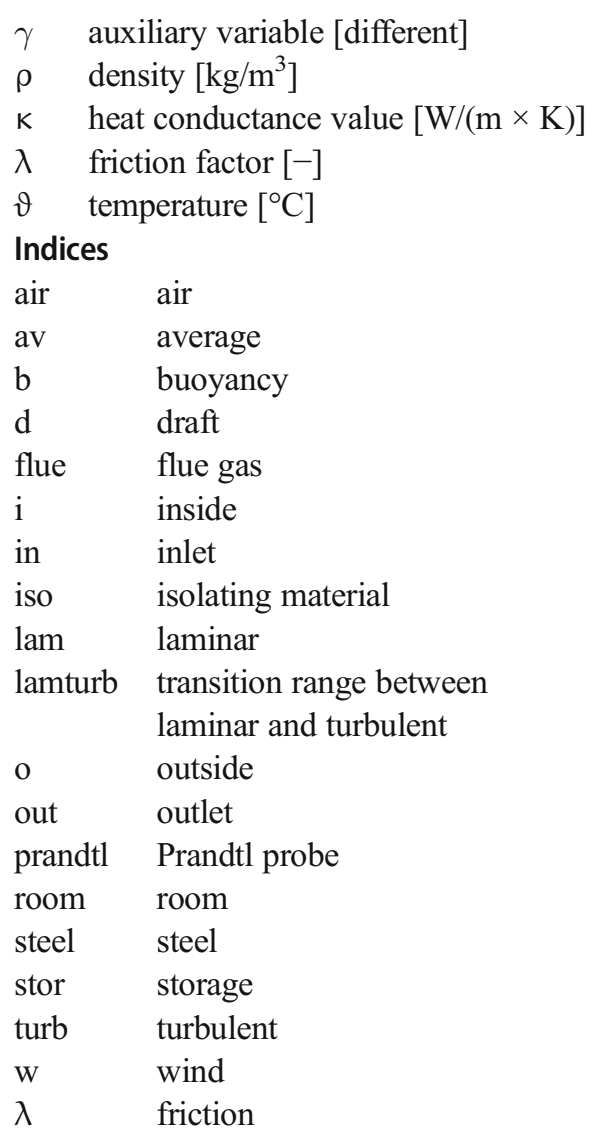




\section{Constants \\ g gravitational constant $\left(9.81 \mathrm{~m} / \mathrm{s}^{2}\right)$ \\ $\mathrm{R}_{\mathrm{m}} \quad$ ideal gas constant $(8.3144598 \mathrm{~J} /(\mathrm{mol} \times \mathrm{K}))$ \\ $\pi \quad$ pi (3.14159)}

\section{Introduction}

Characterization of single room heaters according to their airborne emissions is a serious duty, as avoiding of health risks is an important responsibility of governments. To set up regulations, three aspects have to be considered: (i) acceptable emissions, (ii) derived emission limits, and (iii) an appropriate measuring regulation to have a reproducible and significant result. Acceptable emission levels are often set up based on a lot of scientific studies and on political compromises according to existing base levels of emissions. Then, first difficulty is to come to an appropriate transition calculation to set up the emission levels. Very often the regulations are another political compromise between existing knowledge, state of the art of technical reduction options, and the market. Last but not least, the limits are strongly connected to the measurement setup. Here again, a compromise is necessary between reproducibility, comparability to real-life emissions, and costs of the procedure.

For single room heaters, one of the major emission sources is the starting phase [1]. Thus, a recording of the startup process for the assessment of these heaters is crucial [2]. As long as these furnaces do not have an (emission controlled) electrical fan, they depend on natural draft of the chimney. This draft depends on the chimney size (diameter, height) as well as material, outside weather conditions, the single room heater, inside conditions, and the behavior of the operator.

Most single room heaters (except pellet stoves) are operated on natural draft. In Europe, the existing measurement regulation for type testing [3] sets a fixed draft of typically $12 \mathrm{~Pa}$ or as recommended by the manufacturer of the single room heater and starts the emission measurement after preheating the single room heater, so that every measurement is done on a well-operating hot furnace. This makes the measurements more reproducible, but the conditions of the type testing deviate from the real operating conditions at the user [1]. Similarly, the emissions vary with changing draft conditions; the thermal efficiency decreases with increasing draft [4]. Thus, the real emissions could deviate significantly from the type testing results. Especially for single room heaters without a fan, there is a very intensive discussion [5] about adjusting the existing measuring regulations DIN EN 13240:2001 [3] (European BeReal project [6], German "Blauer Engel" [7]).

In the USA, the type tests of single room heaters [8] are carried out on a natural draft test stand. The flue gas is extracted via a hood and diluted accordingly with the ambient air. These conditions are closer to the user's real operating conditions, but repeatability may also be limited due to changing environmental conditions (e.g., the temperature of the test room).

\section{Objectives}

The objective of this paper is to describe a method of simulating the natural draft, which can be used to measure single room heaters for test purposes. This aims in particular at the reproducible measurement of air pollutants during the operation under these conditions.

\section{Methodology}

The described model combines all the necessary assumptions in the fields of heat transfer, fluid mechanics, and experimental setup, allowing a real-time simulation with good match between simulation and reality, as will be shown in this paper.

The main feature of the model is that it is a pure physical simulation. This means that it does not need any adjustment coefficients or needs to be calibrated, as long as the user knows the basic data of his measuring place (e.g., chimney and insulation geometry, material data, room and outside temperature). Another advantage is the low number of sensors and the cost-effective components for technical implementation.

Basically, this is a 1D forward simulation, which means that the current result is always dependent on all events in the past since simulation has started. Accordingly, the simulation cannot be started or stopped arbitrarily.

\subsection{Test rig}

For the development and validation of the simulation code, the following experimental setup of a natural draft chimney, which is shown schematically in Fig. 1, was used to record the data. This chimney consists of 3 sections, has a total height of $4.75 \mathrm{~m}$, and is connected directly to the upper output of a stove. In Sections 1 and 2 of the chimney, the required sensors for measurement and simulation are installed.

The three-part construction was necessary because the diameter of the stove exit, the measuring section, and the chimney on the roof are different. Table 1 shows the data of the three sections, respectively. All sections are made of $0.6-\mathrm{mm}$ thick stainless steel tubes. Sections 1 and 2 were subsequently insulated with a $30-\mathrm{mm}$ thick insulation of rock wool; Section 3 consists of a double-walled chimney pipe with integrated insulation of also $30 \mathrm{~mm}$. The height of the pipe crossings has been added to the height of Section 2.

To record the wind speed, an anemometer was mounted at the top of the chimney laterally at a distance of approximately $50 \mathrm{~cm}$. 
The test setup has 2 measuring points (MP), on which the necessary sensors for measuring data acquisition are installed. At measuring point 1, the flue gas inlet temperature for the simulation and the draft is recorded. At measuring point 2, the differential pressure is detected by means of a Prandtl probe and the flue gas temperature in order to determine the volume flow. These are recorded every second and used by the simulation. Table 2 shows all parameters recorded. The remaining parameters are recorded manually before the start of the test and are then assumed to be steady state during the simulation.

The data acquisition system consists of an USB-6008 module from National Instruments for recording the analogue signals from the pressure sensors and an USB-4718 module from Advantech for recording the temperatures. The programming for measured value acquisition and simulation was done in LabView.

\subsection{Model for natural draft simulation}

As shown below, natural draft is essentially based on density differences in fluids, which creates buoyancy and creates a flow. The differences in density can be caused by differences in the humidity, the temperature, or the composition of the fluid. In the case of natural draft on a furnace, the temperature difference between the outside air and the hot flue gas is the main force. Wind and friction of the flue gas in the chimney also have an effect on natural draft.

This major relationship is illustrated in Eq. 1 and is based in part on fluid statics and fluid dynamics. The natural draft $p_{d}$ consists of the pressure components of the buoyancy $p_{b}$ and wind $p_{w}$ together. The friction of the flowing flue gas in the chimney creates a pressure loss $p_{\lambda}$. The value describes the difference between the static pressures in the chimney and the static atmosphere in the room.

$\mathrm{p}_{\mathrm{d}}=-\mathrm{p}_{\mathrm{b}}-\mathrm{p}_{\mathrm{w}}+\mathrm{p}_{\lambda}$

Since the chimney model has a modular design, the calculation is also carried out section by section, as shown in Eq. 2 . The current flue gas temperature is transferred at each section boundary. Likewise, in each section, the thermodynamic mean temperature is used to calculate all other dependent values.

$\mathrm{p}_{\mathrm{d}}=-\mathrm{p}_{\mathrm{w}}+\sum_{\mathrm{j}=1}^{\mathrm{n}}\left(\mathrm{p}_{\lambda, \mathrm{j}}-\mathrm{p}_{\mathrm{b}, \mathrm{j}}\right)$

\subsubsection{Buoyancy}

According to the fluid static and the principles of Archimedes, the buoyancy force depends on density difference, volume, and gravity [9]. The pressure component by the buoyancy can be calculated by dividing the resulting buoyancy force of the fluid in the chimney by the base area. Accordingly, the draft is dependent on the height and density differences of the fluids. This is shown in Eq. 3.

$\mathrm{p}_{\mathrm{b}}=\mathrm{g} \times \mathrm{h} \times\left(\rho_{\text {air }, \mathrm{o}}-\rho_{\text {flue }, \mathrm{av}}\right)$

The density of the flue gas and the outside air is calculated using the ideal gas law $[10,11]$ according to Eq. 4. Due to the location of the test site (Leipzig, Germany), the pressure is set as a first approximation as normal pressure with $101.325 \mathrm{kPa}$. After evaluation and measurements of real combustion processes, a constant average molar mass of $29.559 \mathrm{~g} / \mathrm{mol}$ is assumed for the flue gas.

$\rho=(p \times M) /\left(R_{m} \times T\right)$

To calculate the average flue gas temperature in a chimney section, many factors have to be considered, many of which have a mutual influence. These influences include, e.g., the flow rate of the flue gas, the temperature of the chimney, or the external conditions such as temperature and wind speed. Due to these many influences, an implicit calculation method was chosen by iteration of the flue gas temperature based on the heat balance. As start value for the iteration, the average flue gas temperature was set equal to the inlet flue gas temperature, and as a convergence criterion, a deviation of the average flue

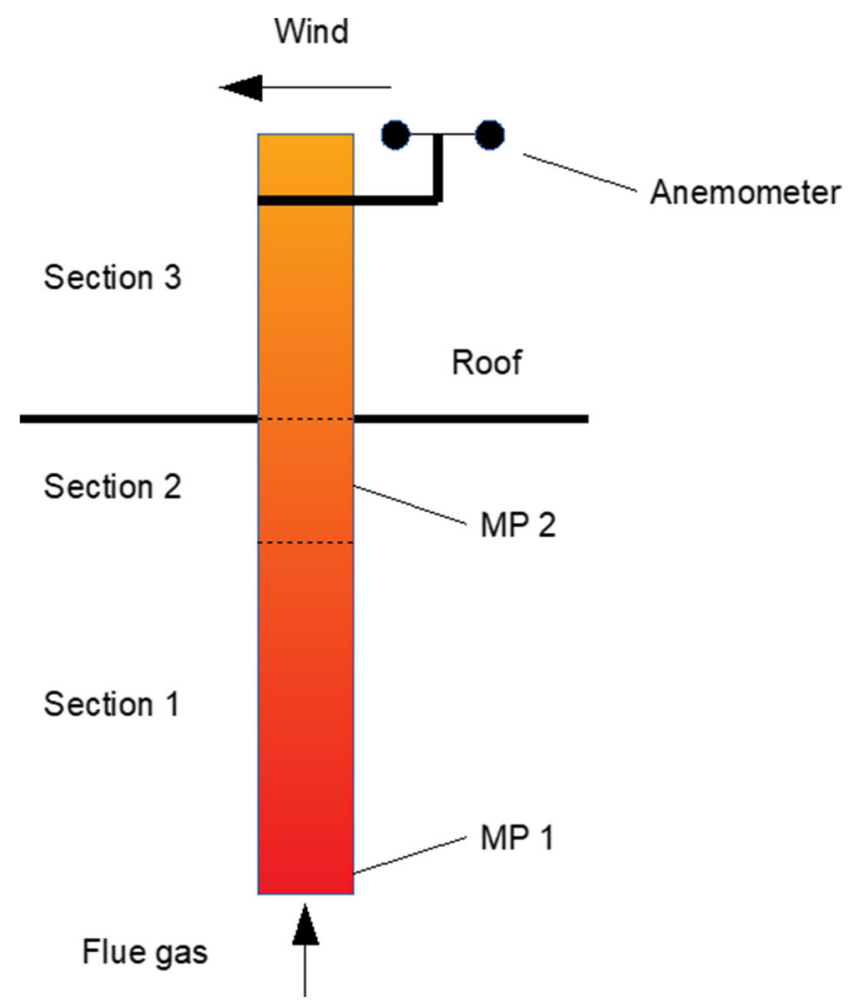

Fig. 1 Schematic representation of the test chimney; MP - measuring point 
Table 1 Technical data of the test chimney

\begin{tabular}{llllll}
\hline Section & $d_{i}[\mathrm{~mm}]$ & $h[\mathrm{~m}]$ & Design type & $x_{\text {iso }}[\mathrm{mm}]$ & $\kappa_{\text {iso }}[W /(m \times K)]$ \\
\hline 1 & 150 & 2.20 & Single-walled & 30 & 0.04 \\
2 & 130 & 0.75 & Single-walled & 30 & 0.04 \\
3 & 140 & 1.80 & Double-walled & 30 (integrated) & 0.04 \\
\hline
\end{tabular}

gas temperature of $1 \mathrm{mK}$ was chosen in the simulation. The convergence of the system is very good and usually requires only 3-4 calculation runs.

The following assumptions have been made for the balance. In order to calculate as quickly as possible, appropriate simplifications have been added.

1. $\dot{Q}_{\text {out }}=\dot{Q}_{\text {in }}-\dot{Q}_{\text {stor }}$

2. Due to its thin thickness, the steel is ideal for heat conduction, is not considered in terms of geometry, but has its mass and heat storage capacity.

3. A pipe shape was assumed for the calculation of the heat transfer through the insulating material.

4. For the calculation of the average temperature of the insulating material, a linear radial temperature distribution was adopted.

The heat transfer and storage in the chimney with these assumptions are calculated by the following equations. The calculation order corresponds to that within the simulation. Equations 5 to 7 correspond to the standard equations for the calculation of the heat transmission coefficient through a wall $[12,13]$.

$k A_{l}=(2 \times \times h) /\left(1 /\left(\alpha_{i} \times d_{i} / 2\right)\right)$

$k A_{2}=(2 \times \times h) /\left(\ln \left(d_{o} / d_{i}\right) / \kappa_{\text {iso }}+1 /\left(\alpha_{o} \times d_{o} / 2\right)\right)$

$k A_{3}=(2 \times \times h) /\left(1 /\left(\alpha_{o} \times d_{o} / 2\right)\right)$

$\left.\gamma_{1}=-\left(k A_{1} / h\right) /\left(\dot{m}_{\text {flue }} \times c_{\text {flue }}\right)\right)$

$$
\begin{aligned}
& T_{\text {flue,out }}=e^{\left(\gamma_{1} \times h\right)} \times\left(T_{\text {flue }, \text { in }}-T_{\text {steel }}\right)+T_{\text {steel }} \\
& T_{\text {flue }, \text { av }, \text { new }}=\left(\left(T_{\text {flue, in }}-T_{\text {steel }}\right) \times\left(e^{\left(\gamma_{1} \times h\right)}-1\right)\right) /\left(\gamma_{1} \times h\right)+T_{\text {steel }}
\end{aligned}
$$

$\gamma_{2}=m_{\text {steel }} \times c_{\text {steel }}+m_{\text {iso }} \times c_{\text {iso }} / 2 \times\left(1+\mathrm{kA}_{2} / \mathrm{kA}_{3}\right)$

$T_{\text {steel,new }}=\left(k A_{1} \times\left(T_{\text {flue,av }}-T_{\text {steel }}\right)-k A_{2} \times\left(T_{\text {steel }}--T_{\mathrm{o}}\right)+T_{\text {steel }} \times \gamma_{2}\right) / \gamma_{2}$

$T_{\text {iso,new }}=\left(\left(1+k A_{2} / k A_{3}\right) \times T_{\text {steel,new }}+\left(1-k A_{2} / k A_{3}\right) \times T_{o}\right) / 2$

The masses of steel and insulant material are calculated as follows. The respective densities and heat capacities were taken from the data sheets $[14,15]$. During installation, the insulation material is compressed toward the inside, which is why the outer diameter is used as the relevant parameter for the calculation. Since the chimney is bent from thin metal sheets and the formulas of the model have been aligned as far as possible to the input parameters, approximately the inner diameter and the wall thickness are used for the calculation of the metal weight. For a standard exhaust pipe with a $150 \mathrm{~mm}$ inner diameter and a wall thickness of $0.6 \mathrm{~mm}$, the error is $0.4 \%$ compared to the exact calculation based on the circular area. This becomes larger, the smaller the diameter or the greater the wall thickness becomes. However, an adaptation of the calculation formula may be necessary depending on the application or may be used directly if desired.

$m_{\text {steel }}=x_{\text {steel }} \times d_{i} \times \times h \times \rho_{\text {steel }}$
Table 2 Used sensors and measuring points; the automatically recorded values are measured continuously

\begin{tabular}{lccc}
\hline Measurand & Measuring point & Sensor & Measuring method \\
\hline $\mathrm{T}_{\text {flue,in }}$ & MP 1 & Type K thermocouple & Automatic (1 s) \\
$p_{d}$ & MP 1 & Sensirion SDP1000-L05 & Automatic (1 s) \\
$\mathrm{dp}_{\text {prandtl }}$ & MP 2 & Sensirion SDP1000-L05 & Automatic (1 s) \\
$\mathrm{T}_{\text {flue,prandtl }}$ & MP 2 & Type K thermocouple & Automatic (1 s) \\
$\mathrm{T}_{\text {room }}$ & Room & Voltcraft BL-20TRH & Manual \\
$\mathrm{T}_{\text {air,o }}$ & Outside & Voltcraft BL-20TRH & Manual \\
\hline
\end{tabular}


Fig. 2 Schematic representation of the simulation program

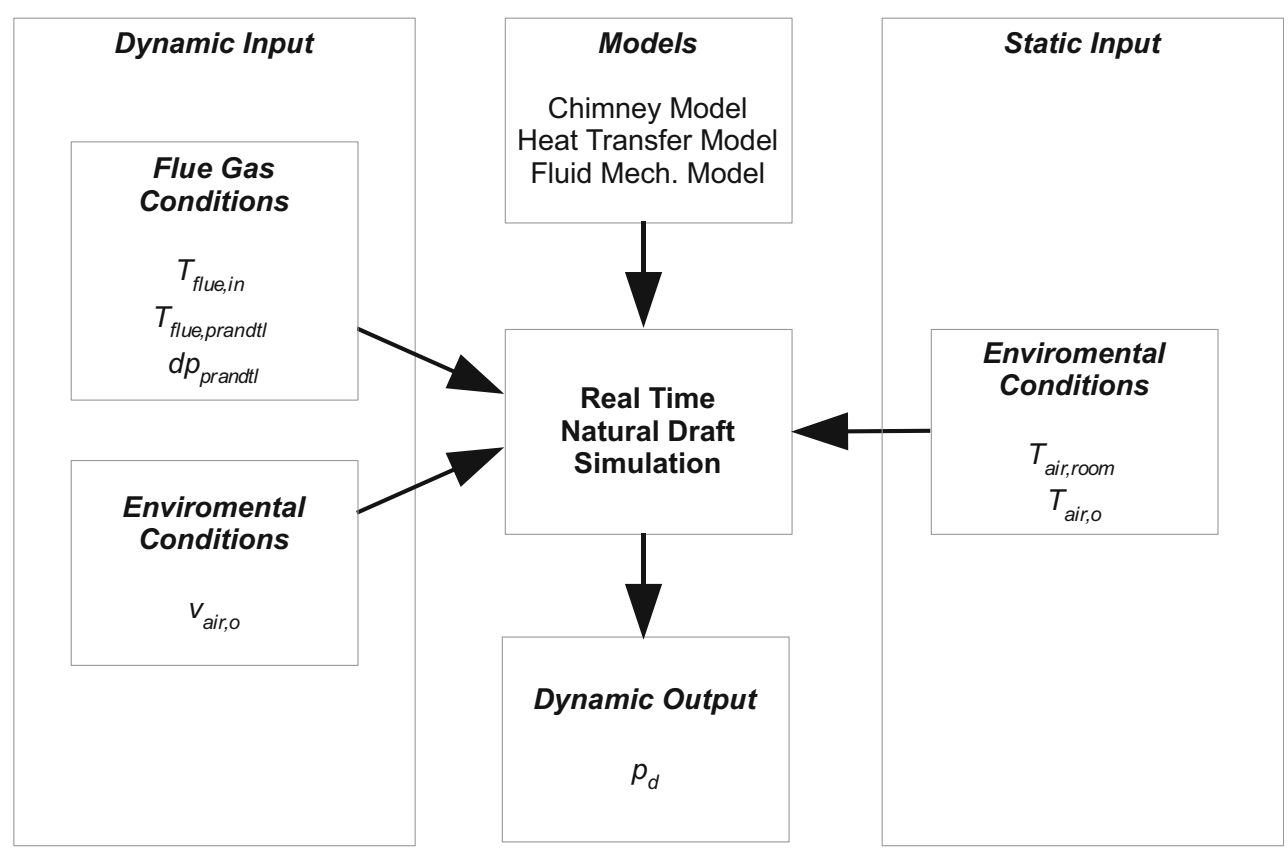

$m_{\text {iso }}=\left(d_{o}-d_{i}\right) / 2 \times d_{o} \times \times h \times \rho_{\text {iso }}$

The heat capacity of the flue gas is calculated as a function of the flue gas average temperature on the basis of available gas data [16].

The thermal conductivity of the insulation $\kappa_{i s o}$ is calculated as a function of the temperature according to Eq. 16. The formula was generated using the data in the data sheet of the insulation material [14].

$$
\begin{aligned}
\kappa_{\text {iso }}= & 4.81481481 \times 10^{-7} \times \vartheta_{\text {iso }}^{2}+1.91481481 \\
& \times 10^{-4} \times \vartheta_{\text {iso }}+3.6037037 \times 10^{-2}
\end{aligned}
$$

The mass flow of the flue gas $\dot{m}_{f l u e}$ is calculated according to Bernoulli $[17,18]$ using the differential pressure of the Prandtl probe and the flue gas temperature at measuring point 2 as well as the chimney diameter according to Eq. 17. As a result, using the temperature at each relevant point of the chimney, the flow rate can be determined for further calculation.

$\dot{m}_{\text {flue }}=d^{2} / 4 \times \pi \times \operatorname{sqrt}\left(2 \times d p_{\text {prandtl }} / \rho_{\text {flue,prandtl }}\right) \times \rho_{\text {flue,prandtl }}$

An approximate formula [19] is used to calculate the inner heat transfer and is shown in Eq. 18. The flow rate can be calculated on the basis of the determined flue gas mass flow and the flue gas density.

$\alpha_{i}=4.4 \times v_{\text {flue,av }}^{0.75} / d_{i}^{0.25}$

$v_{\text {flue }, \text { av }}=\dot{m}_{\text {flue }} /\left(\left(d_{i}^{2} / 4 \times \pi\right) \times \rho_{\text {flue }, a v}\right)$
Proximity formulas [20] are also used for the external heat transfer. Since the same calculation is used for the inner and outer segments of the chimney, natural (Eq. 21) and forced convection (Eq. 23) values are always calculated. Only when the value for forced convection exceeds the value of natural convection will it be used for calculation (Eq. 20).

$\alpha_{o}=\left\{\begin{array}{cc}\alpha_{o, 1}, & \alpha_{o, 2}<\alpha_{o, 1} \\ \alpha_{o, 2}, & \alpha_{o, 2} \geq \alpha_{o, 1}\end{array}\right.$

$\alpha_{o, 1}=1.32 \times(\mathrm{dT} / \mathrm{h})^{0.25}$

$d T=T_{\text {steel }}-2 \times\left(T_{\text {steel }}-T_{\text {iso }}\right)-T_{o}$

$\alpha_{o, 2}=8.9 \times v_{o}^{0.9} / \mathrm{d}_{\mathrm{o}}{ }^{0.1}$

\subsubsection{Friction}

Friction is a component of the fluid dynamics and can be calculated as shown in Eq. 24 according to Bernoulli's principle [11, 17].

\begin{tabular}{|c|c|c|c|}
\hline Experiment & $\begin{array}{l}\text { Room } \\
\text { temperature } \\
\vartheta_{\text {air,room }}\left[{ }^{\circ} \mathrm{C}\right]\end{array}$ & $\begin{array}{l}\text { Outside } \\
\text { temperature } \\
\vartheta_{\text {air,o }}\left[{ }^{\circ} \mathrm{C}\right]\end{array}$ & $\begin{array}{l}\text { Mean wind } \\
\text { speed } \\
\mathrm{v}_{\text {air,o }}[\mathrm{m} / \mathrm{s}]\end{array}$ \\
\hline 1 & 23.0 & 24.5 & 0.56 \\
\hline 2 & 26.5 & 27.1 & 0.51 \\
\hline 3 & 22.6 & 21.7 & 0.67 \\
\hline 4 & 25.0 & 24.1 & 2.55 \\
\hline
\end{tabular}

Table 3 Environmental conditions during the experiments 
Table 4 Statistical values for the deviation between real and simulated draft

\begin{tabular}{lll}
\hline Experiment & Mean error $[\mathrm{Pa}]$ & Maximum error $[\mathrm{Pa}]$ \\
\hline 1 & $0.54 \pm 0.40$ & 2.54 \\
2 & $0.51 \pm 0.42$ & 2.67 \\
3 & $0.83 \pm 0.67$ & 3.70 \\
4 & $3.13 \pm 3.16$ & 31.27 \\
\hline
\end{tabular}

$p_{\lambda}=\left(\rho_{\text {flue,av }} \times v_{\text {flue }, \mathrm{av}}^{2} \times \lambda \times h\right) /\left(2 \times d_{i}\right)$

The friction factor is calculated using the approximate equations of Hagen-Poiseuille [18, 21] (Eq. 26) in laminar $(\operatorname{Re} \leq 2320)$ and Blasius $[21,22]$ (Eq. 27) in the turbulent range $\left(2320>\operatorname{Re}>10^{5}\right)$. For the calculation, it is assumed that the chimney is hydraulically smooth. The limit of both equations is different at $\mathrm{Re}=$ 2320 , and thus a discontinuous function over the considered range arises. Since this is not permissible for the simulation, a transition range (Eq. 28) is created (2000 $<\operatorname{Re}<2600$ ), in which the function values are linearly approximated on the basis of the limit values of the interval. This creates a continuous function in the entire area and can be used for the simulation (Eq. 25).

$$
\begin{aligned}
& \lambda=\left\{\begin{array}{c}
\lambda_{\text {lam }}, \quad R e \leq 2000 \\
\lambda_{\text {lamturb }}, \quad 2000<R e<2600 \\
\lambda_{\text {turb }}, \quad R e \geq 2600
\end{array}\right. \\
& \lambda_{\text {lam }}=64 / R e_{i} \\
& \lambda_{\text {turb }}=0.3164 / \mathrm{Re}_{\mathrm{i}}{ }^{0.25}
\end{aligned}
$$

$\lambda_{\text {lamturb }}=\left(1-\gamma_{3}\right) \times \lambda_{\text {lam2000 }}+\gamma_{3} \times \lambda_{\text {turb2600 }}$

$\lambda_{\operatorname{lam} 2000}=64 / 2000$

$\lambda_{\text {turb2600 }}=0.3164 / 2600^{0.25}$

$\gamma_{3}=\left(R e_{i}-2000\right) / 600$

The representation for the calculation of the Reynolds number is omitted here.

\subsubsection{Wind}

The influence of the wind on the chimney draft depends on many different parameters. These include the environment with possibly turbulences, the roof pitch, or any existing chimney construction (rain protection, etc.) [23]. For this work, only the reduction of the static pressure by the wind speed according to Bernoulli was assumed. This relationship is shown in Eq. 32 [17, 18].

$\mathrm{p}_{\mathrm{w}}=\left(\rho_{\mathrm{air}, \mathrm{o}} \times \mathrm{v}_{\mathrm{air}, \mathrm{o}}^{2}\right) / 2$

\subsection{Structure of the simulation program}

Figure 2 shows the schematic structure of the natural draft simulation. As mentioned, the submodels as well as the environmental conditions are steady state, and only the data of the sensors are used as dynamic input. From this, the draft is then calculated in real time.
Fig. 3 Real and simulated course of experiment 1

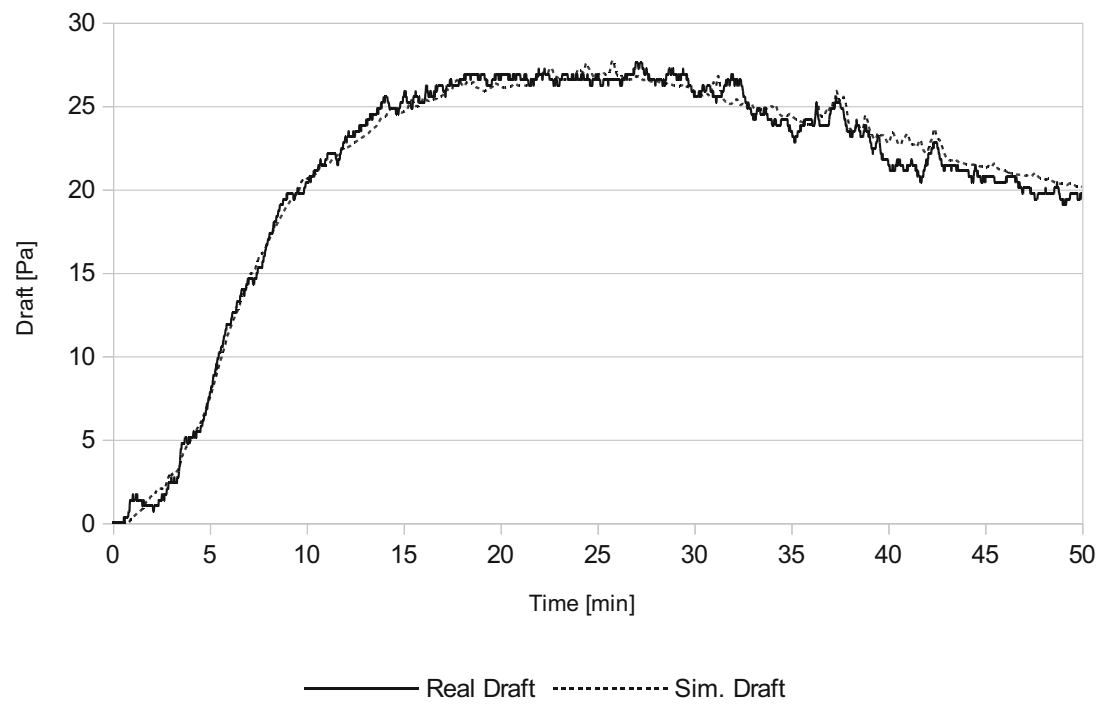


Fig. 4 Real and simulated course of experiment 2

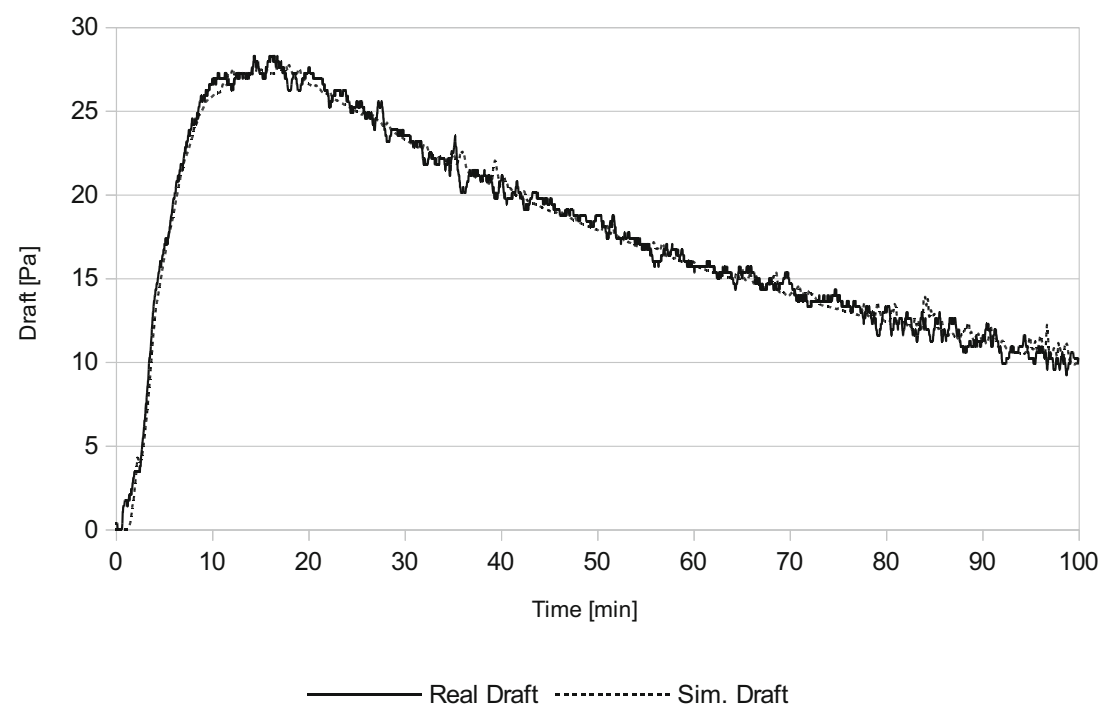

\subsection{Execution of the test}

The experiments were carried out with a model Ystad stove from Haas + Sohn Ofentechnik GmbH. As fuel, air-dried beech wood was chosen, which was ignited from below to ensure the steepest ascent of the draft. The fuel load was $1.5 \mathrm{~kg}$ each. In each case, only one burnup took place in the cooled wood-burning stove with desired test duration of $100 \mathrm{~min}$. After burning, the oven was opened for optimal cooling. During the tests, it was ensured that blowers on other test stands could not create a vacuum in the room where the test rig was installed.

Experiments were conducted on three almost windless days and one windy day in order to be able to observe the influences separately. Table 3 shows the environmental conditions for the selected experimental days over the duration of the experiments.

\section{Results}

The results of the experiments and simulations can be subdivided into three partial results: the simulation of the natural draft in almost windless atmosphere, the simulation under windy conditions, and a parameter variation of the natural draft simulation.

Table 4 shows the statistical error values regarding the deviation from reality and simulation. For this purpose, the absolute value of the difference between the real and the simulated draft was built at each measuring point, and the mean and standard deviation was calculated over the duration of the experiment. These are on average for all experiments in an almost windless atmosphere well below $1 \mathrm{~Pa}$.
Fig. 5 Real and simulated course of experiment 3

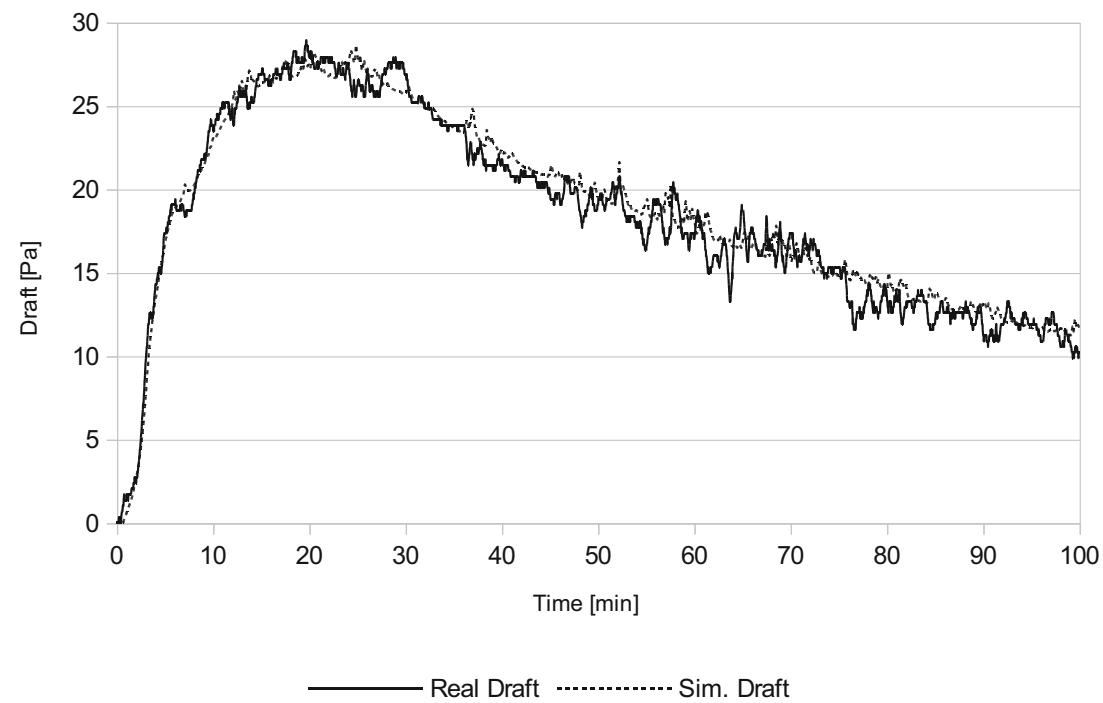


Fig. 6 Real and simulated course of experiment 4

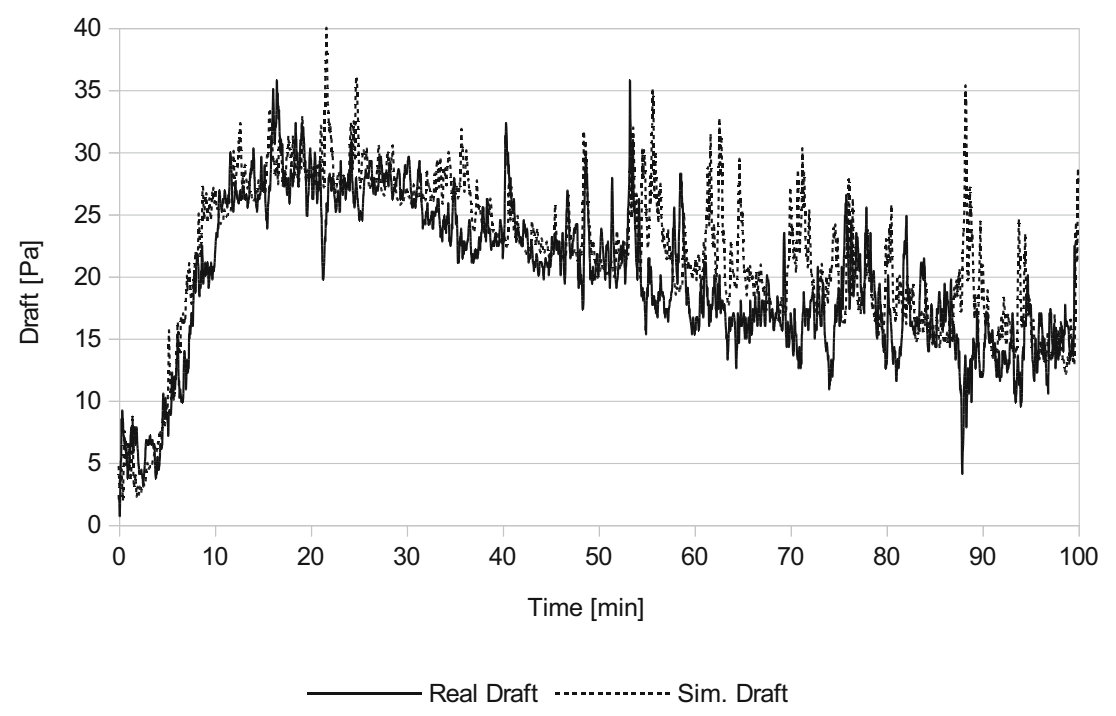

\subsection{Simulation of the natural draft in almost windless atmosphere}

Figures 3, 4, and 5 show the test results in an almost windless atmosphere. In experiment 1 , there was a problem with the power supply during the data recording; that is why only the course of $50 \mathrm{~min}$ and not of $100 \mathrm{~min}$ is shown. In contrast to Eq. 1, the results are presented with a positive sign for better clarity.

It turns out that the courses are basically very good in terms of the deviation between reality and simulation, especially the lower the wind influence. Also, the most interesting part of the heating, which is characterized by a steep rise of the draft, is simulated well and without overshoot. It is noticeable that the different burn rates, the maximum of which was reached in the draft between 15 (Fig. 4) and 25 min (Fig. 3), did not affect the quality of the result.

\subsection{Simulation of the natural draft under windy conditions}

Figure 6 shows a course with turning winds with a maximum speed of over $5 \mathrm{~m} / \mathrm{s}$. As mentioned before, it is assumed in the model approach that in the room there is the pressure of a static atmosphere. Due to the structural conditions, the wind could sometimes flow past the openings for fresh air at high speed laterally in the case of an unfavorable wind direction. This airflow causes the pressure in the room to drop, which also causes the measured draft to drop. If the flow velocity at the opening is smaller than at the chimney, but greater than zero, the actual increase in draft due to the wind is less than simulated. If the speed at the opening is greater than at the chimney, there is even a negative correlation (broken line marks in Fig. 7). In minute 88 (Fig. 6) can be seen in the course that began a strong gust of wind. The wind direction
Fig. 7 Real and simulated course of experiment 4; continuous line marks, good correlation; broken line marks, negative correlation

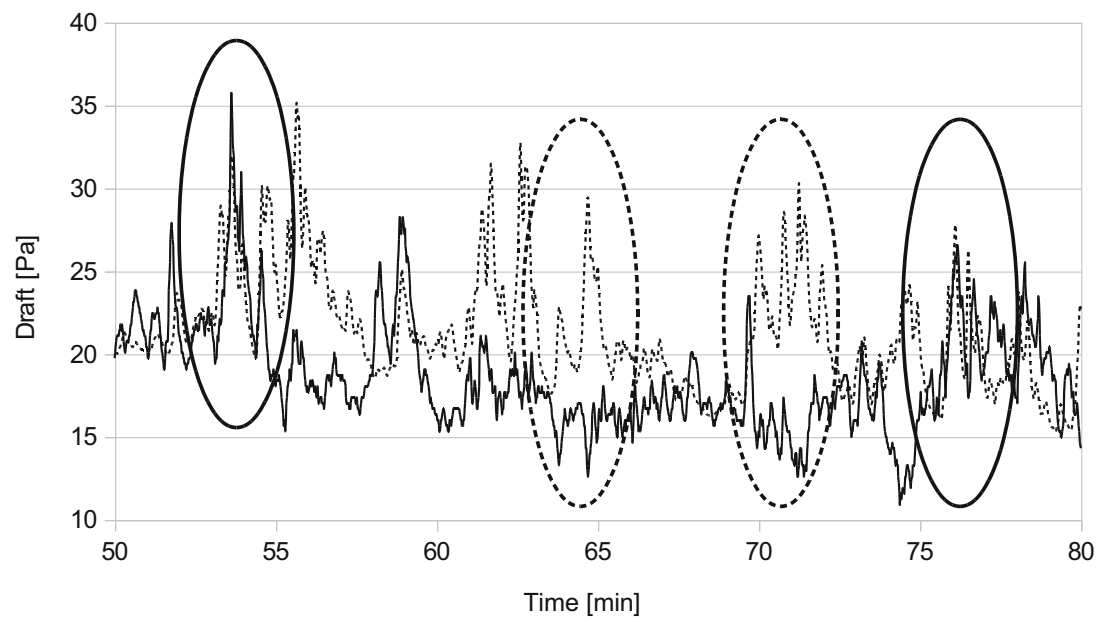


Fig. 8 Simulated course of experiment 2 with courses of 3 cases (case 1, massless chimney; case 2, without outer heat transfer; case 3 , without inner heat transfer

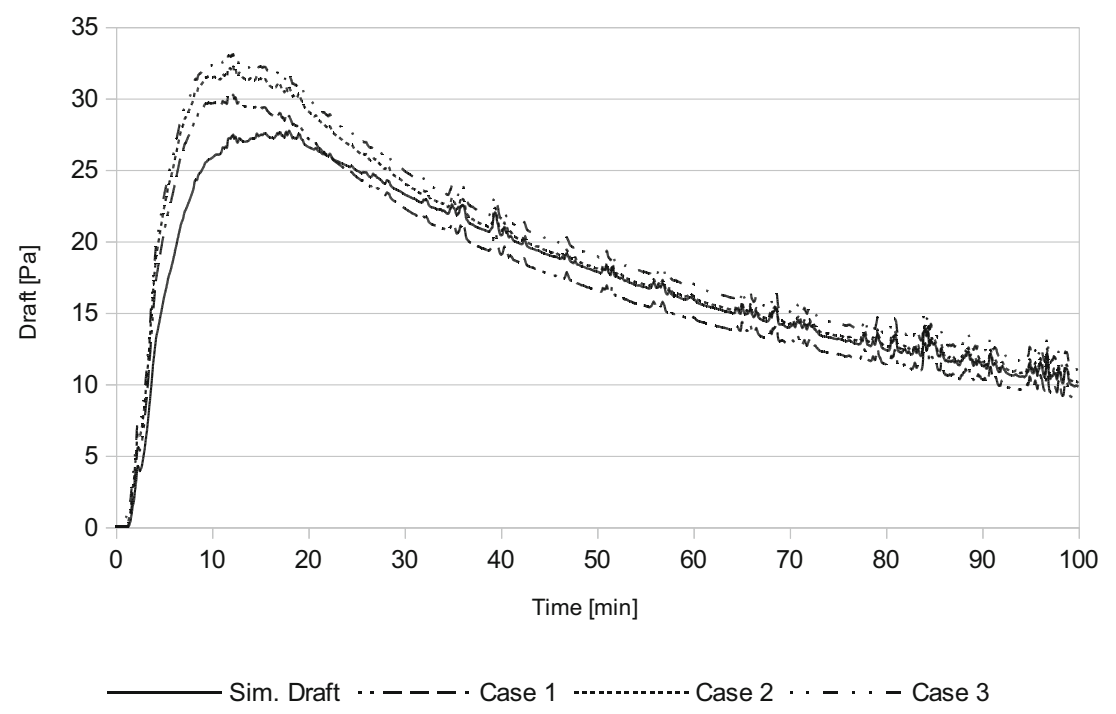

did not correspond to the model assumptions mentioned above, whereby at that moment a very large error of over $30 \mathrm{~Pa}$ occurred between simulation and reality.

In the course of the recording, the wind has turned several times strongly, so there were phases where simulation and reality were well-aligned (continuous line marks in Fig. 7) and phases where the correlation even became negative (broken line marks in Fig. 7). This problem is based on the basic assumption of the model that there is the pressure of a static atmosphere in the room. For a better replica in this point, the wind speed at the point of pressure equalization would also have to be recorded and considered. However, it also shows that in the short phases in which this basic assumption is actually depicted, reality and simulation agree well. That proofs that there is not an up-summing deviation due to the change of wind direction.

\subsection{Simulation of the natural draft with change of basic assumptions}

Figure 8 shows variations of the natural draft simulations from experiment 2 . In addition to the natural draft simulation according to the illustrated model, simulation results are also presented with the assumption of a massless chimney, without outer and inner heat transfer.

As expected, all courses are significantly above the real simulated course, especially during the startup phase. In the massless scenario (case 1), this is due to the fact that the flue gas is not initially cooled by the still cold chimney, which generates a higher draft. In the further course, the draft is below that of the real simulated, as the massless chimney with decreasing flue gas temperatures cannot transport stored energy back to the flue gas. Although the storage mass of the chimney can be used in the scenario without outer heat transfer (case
2). No energy is released into the surrounding area, which means that the course is significantly above the real one, especially during the startup phase. Later, however, the course again corresponds to the real simulated draft. In the scenario without inner heat transfer (case 3), the entire course is above the real simulated course. Since no heat losses cool the flue gas, this case corresponds to the highest possible draft and can be called adiabatic.

Table 5 shows the statistical error values regarding the deviation from reality and simulation of the different cases. It turns out that both average and maximum errors are significantly higher in all other scenarios.

As shown in Fig. 8, the deviation in the firing phase is highest. Figure 9 shows in detail the respective courses of the deviation between simulation and reality for this phase. It can be seen that in the assumed cases, which represent a simplification of the model, especially at this stage, the error first increases sharply and then decreases again with the further course. In contrast, in the model presented, the deviation remains low over the entire course, and the simulation has a constant quality.

Table 5 Statistical values for the deviation between real draft and draft of the simulated cases of experiment 2

\begin{tabular}{ccc}
\hline Simulation mode & Mean error $[\mathrm{Pa}]$ & Maximum error $[\mathrm{Pa}]$ \\
\hline Simulated draft & $0.51 \pm 0.42$ & 2.67 \\
Case 1 & $1.36 \pm 0.91$ & 4.86 \\
Case 2 & $1.29 \pm 1.60$ & 6.63 \\
Case 3 & $1.99 \pm 1.71$ & 7.48 \\
\hline
\end{tabular}


Fig. 9 Draft error between real draft and draft of the simulated cases of experiment 2

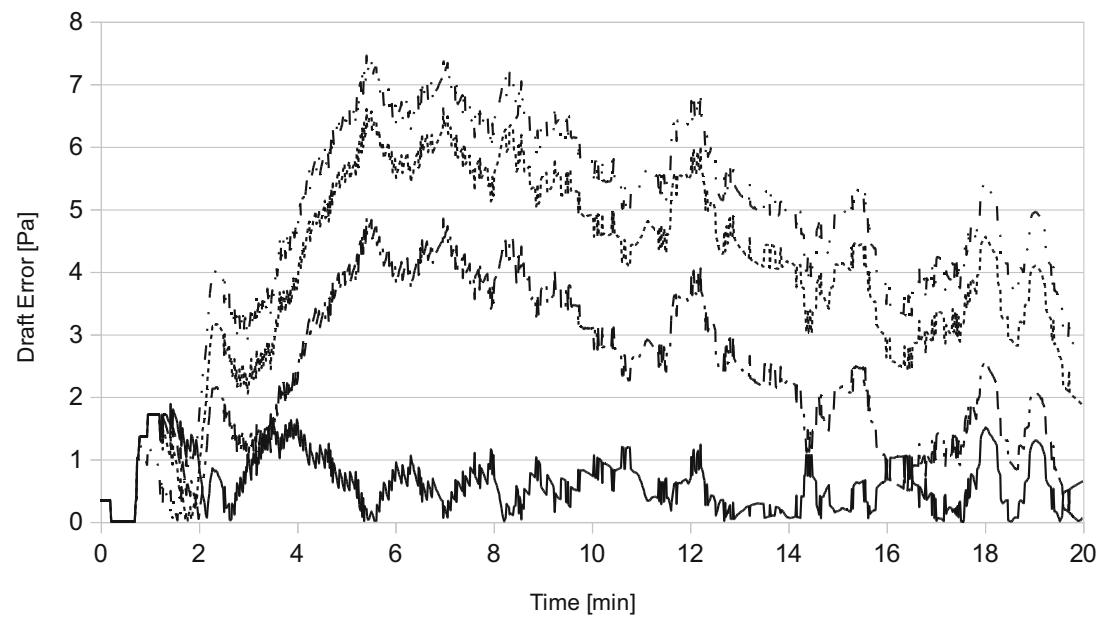

— Sim. Draft $\cdots--$ - Case 1 -........- Case 2 . - . - Case 3

\section{Conclusion and outlook}

Due to the constantly changing parameters such as outside temperature and wind, natural draft measurements on real chimneys cannot be reproduced with high accuracy. Even if natural draft systems are constructed for research purposes in a room with flue gas extraction, the parameters influencing the seasons and the duration of the test cannot be fully controlled. Also, an adaptation of the chimney geometry is not possible in many cases. The system described here allows reproducibility of natural draft conditions with completely free choice of parameters such as outside temperature and chimney geometry and has a very high accuracy in the simulation of a real natural draft chimney in the case of windless conditions. This means that experiments can be repeated under the same conditions, and thus other factors under real conditions can be investigated, such as the burning behavior under different climatic conditions or chimney heights.

It was also shown that due to the complexity of the wind, a simulation of the natural draft under windy conditions cannot be carried out with the given assumptions with satisfactory accuracy. However, as the model is intended in particular to improve the current measurement and approval procedures for the measurement of single room heater combustion, the consideration of wind influence is of minor importance. Should future application fields arise, in which the wind influence on the natural draft or the behavior of single room heaters under windy conditions should be investigated, the model mentioned must be extended by a more complex wind model and tested again under these conditions.

For a practical application, the system should be extended so that a control imprints the simulated natural draft with the highest possible accuracy on the fire place, so that it behaves like a real natural draft chimney.
Measuring instruments which remove flue gas from the chimney (e.g., dust measurement) also have direct influence on the natural draft. Since this advanced system would be insensitive to disturbances that occur after the temperature and volumetric flow measurement, these gauges no longer influence the experiment.

In addition, many standards only measure selected periods of burnup. With such a system, it would be possible to reproducibly measure the complete burnup and to record the emissions over the entire burnup period. This would allow a more realistic estimate of the emissions that would occur to a user and would give furnace developers the chance to test their developments on reproducible and much more realistic conditions.

Open Access This article is distributed under the terms of the Creative Commons Attribution 4.0 International License (http:// creativecommons.org/licenses/by/4.0/), which permits unrestricted use, distribution, and reproduction in any medium, provided you give appropriate credit to the original author(s) and the source, provide a link to the Creative Commons license, and indicate if changes were made.

\section{References}

1. Nussbaumer T et al (2008) Influence of ignition and operation type on particle emissions from residential wood combustion. In: Proceedings of 16th European Biomass Conference and Exhibition, Valencia, Spain, http://www.verenum.ch/ Publikationen/Biomass-Conf9.5.pdf [Access at 05.24.19]

2. Klippel N, Nussbaumer T (2007) Einfluss der Betriebsweise auf die Partikelemissionen von Holzöfen - Projektzusatz $1+2$ zum Projekt Wirkung von Verbrennungspartikeln. Verenum, Zürich ISBN 3908705-15-0, http://www.verenum.ch/Publikationen/ SBOfenmessun.pdf [Access at 05.24.19]

3. DIN EN 13240:2005-10, Raumheizer für feste Brennstoffe Anforderungen und Prüfungen 
4. Reichert $\mathrm{G}$ et al (2017) Effect of draught conditions and ignition technique on combustion performance of firewood roomheaters. Renew Energy 105. https://doi.org/10.1016/j.renene.2016.12.017

5. Reichert $\mathrm{G}$ et al (2018) Novel method evaluating real-life performance of firewood roomheaters in Europe. Energy Fuels $32 \mathrm{https} / /$ pubs.acs.org/doi/10.1021/acs.energyfuels.7b03673

6. http://www.bereal-project.eu/ [Access at 05.24.19]

7. https://www.blauer-engel.de/en [Access at 05.24.19]

8. Method 5G: Determination of particulate matter emissions from wood heaters (dilution tunnel sampling location), https://www. epa.gov/sites/production/files/2017-08/documents/method_5g.pdf [Access at 05.24.19]

9. Siegloch H (2017) Technische Fluidmeachanik, 10. Auflage edn. Springer-Verlag, Berlin ISBN 978-3-662-54466-2

10. Müller I (2001) Grundzüge der Thermodynamik, 3. Auflage edn. Springer-Verlag, Berlin ISBN 978-3-540-42210-5

11. Lyons WC, Plisga GJ (2005) Standard handbook of petroleum \& natural gas engineering, 2nd edn. Gulf Professional Publishing, Burlington ISBN 0-7506-7785-6

12. Baehr HD, Stephan K (2006) Wärme- und Stoffübertragung, 5. Auflage edn. Springer-Verlag, Berlin ISBN 978-3-540-32334-1

13. Rathore MM, Kapuno RRA (2011) Engineering heat transfer, 2nd edn. Sudbury, Jones \& Bartlett Learning ISBN 978-0-7637-7752-4

14. Rockwool Klimarock, Datasheet, https://cdn01.rockwool.de/ siteassets/rw-d/datenblatter/haustechnik/db-klimarock-rockwool. pdf?f=20180622053731 [Access at 05.24.19]
15. Steel 1.4301, Datasheet, https://www.dew-stahl.com/fileadmin/ files/dew-stahl.com/documents/Publikationen/ Werkstoffdatenblaetter/RSH/1.4301_de.pdf [Access at 05.24.19]

16. https://webbook.nist.gov/chemistry/ [Access at 04.25.19]

17. Kurzweil P, Frenzel B, Gebhard F (2008) Physik Formelsammlung - Für Ingenieure und Naturwissenschaftler. Friedr. Vieweg \& Sohn Verlag, Wiesbaden ISBN 978-3-8348-0251-4

18. Larock B, Jeppson R (2000) Watters G: Hydraulics of pipeline systems. CRC Press, Boca Raton ISBN 0-8493-1806-8

19. Schramek R, Recknagel H (2007) Taschenbuch für Heizung + Klimatechnik, 73. Auflage edn. München, Oldenbourg Industrieverlag ISBN 978-3-8356-3104-5

20. DIN EN ISO 12241:2008-11, Wärmedämmung an haus- und betriebstechnischen Anlagen - Berechnungsregeln (ISO 12241: 2008)

21. Grote K-H, Feldhusen J (2014) Dubbel - Taschenbuch für Maschinenbau, 24. Auflage edn. Springer-Verlag, Berlin ISBN 978-3-642-38890-0

22. Purohit K, Harsha SP, Purohit RK (2013) Fluid mechanics. Scientific Publishers (India), Jodhpur ISBN 978-81-7233-816-9

23. Meuth H (1934) Der Einfluß des Windes auf den Kaminzug nach Untersuchungen an Kaminköpfen natürlicher Größe. Berufsarbeit und Wissen

Publisher's Note Springer Nature remains neutral with regard to jurisdictional claims in published maps and institutional affiliations. 